\title{
Problem-Solving, Resource Utilization, and Community Involvement in a Black and a White Community ${ }^{1}$
}

\author{
Roger E. Mitchell ${ }^{2}$ \\ University of Maryland \\ Oscar A. Barbarin \\ University of Michigan \\ Daniel J. Hurley, Jr. \\ University of Rhode Island
}

This study examines differences in use of resource networks and experience of community life as a function of racial composition of community and individuals' roles in the formal service system. Interviews were conducted with service providers and civically active and inactive residents $(\mathrm{n}=102)$. Members of the black community reported fewer community strengths, more service-related community deficits, and a greater reliance on informal resource networks than members of the white community. However, there were no significant differences between members of the towns in community satisfaction. Service providers and civically active citizens reported more community strengths, deficits, problem-solving alternatives, and satisfaction than did civically inactive citizens. A positive relationship between problem-solving style, access to resource networks, and experience

'The data for this study were collected when all of the authors were associated with the Community Field Station, Department of Psychology, University of Maryland, College Park, Maryland. Thanks are due to the many community psychology undergraduate students who assisted in the data collection, as well as to Ed Trickett and anonymous reviewers who provided comments on earlier versions of this manuscript. The authors would also like to thank the Computer Science Center, University of Maryland, for assistance in the data analysis.

${ }^{2}$ All correspondence should be sent to Roger Mitchell, Ph.D., Social Ecology Laboratory, Department of Psychiatry and Behavioral Sciences, Stanford University School of Medicine, Palo Alto, California 94305. 
of community support is suggested. The implications of these findings for community assessment are discussed.

Over the past decade, there has been a continued interest in how community environments influence individual coping and well-being. Iscoe (1974), for example, has argued that the competent community is one in which members "know where and how to acquire resources" and are not overwhelmed by "feelings of helplessness and powerlessness" (p. 609). Similarly, Sarason (1974) suggests that community effectiveness can be measured by the degree to which there is a heightened "psychological sense of community," i.e., the sense that one is involved in a "readily available, mutually supportive network of relationships" (p. 1). Moreover, satisfaction with community life, and participation in its processes, have been related to perceptions of "quality of life" (Campbell, Converse, \& Rodgers, 1976; Marans \& Rodgers, 1975; Zautra, Beier, \& Cappell, 1977; Glynn, Note 1).

More recently, efforts have been made to understand the processes through which community environments influence community satisfaction and participation (Garbarino \& Sherman, 1980; Warren, 1978, 1980; Holohan, Betak, Spearly, \& Chance, Note 2). Creting a typology of neighborhoods, Warren (1980), for example, found that neighborhood context was significantly related to the types of helping transactions occurring within these neighborhoods. This suggests that the increased emphasis on informal helping networks (e.g., Gottlieb, 1979; Gourash, 1978; Froland, Pancoast, Chapman, \& Kimboko, 1981) should be accompanied by an interest in the ecological context within which these networks operate.

One task for community psychologists, then, is to continue to engage in studies that describe how community variables are related to citizen satisfaction and access and use of social resources. The purpose of this study is to examine differences in experience of community life and use of community resources as a function of two variables: racial composition of community, and individuals' roles with regard to formal service systems within the community (i.e., service provider, active citizen, inactive citizen). The following paragraphs describe these variables in more detail.

Racial composition of community is examined in this study because of the renewed interest in understanding the unique attributes of minority communities. To date, much social science research has focused upon the "pathology" within minority communities, e.g., the "deterioration" of the black family (Moynihan, 1965) or the transmission of a "culture of poverty" (Lewis, 1966). Noting that discrimination and low socioeconomic status present special challenges to the coping skills of minority populations, Padilla (1981), nonetheless, argues for a "cultural strength" 
model that would focus on individuals' abilities to utilize informal networks and maintain adaptive and effective life-styles. Few empirical investigations, however, have compared experience of community life and use of resource networks in demographically similar black and white communities (Hurley, Barbarin, \& Mitchell, in 1981).

The role of the individual with regard to community service systems may also affect resource utilization, problem-solving, and experience of community life. Greenberg (1974), for example, suggests that participation in different community institutions may influence one's sense of "community feeling" and create differential access to problem-solving networks. Indeed, differences in views of community priorities and in experience of community life have been found between community residents and service providers (Richardson \& Scutchfield, 1973; Shaver \& Cole, 1973) as well as between civically involved and uninvolved community residents (Carr, Dixon, \& Ogles, 1976). Given the emphasis on citizen participation in community affairs, it would seem important to have a more differentiated picture of the consequences of such involvement. Therefore, the categories of service provider, active citizen, and inactive citizen were devised for this study. A service provider is defined on the basis of formal employment by a service delivery system critical to the community, e.g., school, town government. An active citizen is defined as a person with no such formal role who is actively involved in other community-based groups or activities, e.g., community boards, town meetings, civic associations. An inactive citizen is defined as a citizen who is not involved in collective efforts to monitor or influence the functioning of the formal service systems in his/her community, though he/she may be quite active in other areas.

In summary, then, this study represents an exploratory attempt at examining the manner in which experience of community life (i.e., assessment of community strengths and deficits, sense of satisfaction and support) and use of community resources (i.e., problem-solving, access to influence networks) vary as a function of other system charactristics. The variables chosen here are racial composition of community and individual role status with regard to community service systems.

\section{METHOD}

\section{Participants}

Two communities in the Washington, D.C., metropolitan area that differed significantly in terms of racial composition (one being $90 \%$ white, the other $90 \%$ black) were selected. Both towns were part of the same 
county political structure, and were relatively stable with respect to racial makeup and transience of the population. The white and black communities were similar with regard to median income ( 11,800 vs. 10,797 , respectively) and level of education (12.2 vs. 12.0 median school years completed, respectively), ${ }^{3}$ although they differed in population size (12,933 vs. 7,279, respectively). ${ }^{4}$ Since comparative analysis of minority and white communities is often confounded by differences in socioeconomic variables, the authors chose income and educational level as the primary criteria along which the communities should be similar.

Within each community, members were categorized as either active citizens, inactive citizens, or service providers. As stated previously, service providers $(n=24)$ were defined on the basis of formal employment by a service delivery system. Officials from mental health, public health, juvenile service, social service, family service, church, school, police, fire department, and town government systems within each community were asked to participate. Attempts were made to select persons in leadership positions within these institutions (e.g., a team leader at a mental health clinic, the chief of police, etc.). Only one of the selected service-providers approached refused to participate. Active citizens $(n=32)$ were recruited from town government and civic association meetings by project staff members who explained the purpose of the project and requested volunteers. All interviews with active citizens, as with inactive citizens, took place in the respondents' home. Inactive citizens $(n=42)$ were selected on the basis of a random sampling procedure applied to each town. Blocks were randomly selected using a stratified procedure based on the type of housing (single family vs. apartment). An equal number of households were then randomly drawn from each set of blocks. Undergraduate students trained as interviewers visited these households and explained the nature and purpose of the survey in a standardized fashion. The times and days of the week during which interviewers approached these households were varied, in order to avoid a source of potential bias. Since the survey was done conjointly with the local county health department and was well-publicized, the refusal rate was low (less than 5\% of the individuals approached in each community declined to participate). There were no significant differences between active and inactive citizens with respect to age, sex, or length of residence in their communities.

\section{Measures}

A community survey instrument (Barbarin \& Hurley, Note 3) was developed which included items relating to both experience of community

${ }^{3} 1970$ census data.

${ }^{4} 1975$ census data; data for this study were collected in 1975 . 
(i.e., satisfaction, support, assessment of community strengths and deficits) and competent functioning within the community (i.e., problem-solving, access to information and influence channels). ${ }^{5}$ Survey items are described below.

Community Strengths. An open-ended question asking respondents to name those things which they liked most about the communities in which they lived, or for service providers, in which they worked. For each respondent, the number of responses was totaled, and each response was coded as relating to physical (e.g., geographic location), service (e.g., police protection, good schools), or interpersonal (e.g., friendly neighbors) aspects of the community.

Community Satisfaction. A seven-point Likert scale asking respondents to rate how much they liked living (or working) in their community.

Community Support. A seven-point Likert scale asking residents to rate the probability that neighbors would help them in time of difficulty. Service providers were asked to rate how probable it was that residents would help each other in time of difficulty.

Community Deficits: Numbers. An open-ended question asking respondents to cite the most important community needs which were not being met. As with community strengths, the total number of responses was recorded, as well as the type of response (i.e., physical, service, or people related).

Community Deficits: Rating. Respondents were asked to rate each of 13 community problems along a seven-point Likert scale in terms of degree of severity for the community. These problems included drug abuse, alcoholism, juvenile delinquency, inadequate public transportation, lack of conveniently located stores, inadequate educational facilities, inadequate road maintainance, inadequate upkeep of property, lack of personal safety in the streets, lack of respect for police, lack of services for senior citizens, and lack of emergency home services for the sick and the elderly. An average rating of severity across the 13 community problems was calculated for each respondent.

Problem-Solving: Number of Alternatives. Respondents were asked to respond to hypothetical problem situations related to consumer, mental health, financial, and service planning issues (e.g., "a friend's husband has just left her and the children, and she is becoming more depressed and talks seriously about killing herself.") The average number of alternative solutions per problem was calculated as well as the type of resources relied upon (i.e., personal resources, informal network resources, formal service system resources).

"These variables have been derived from a model of community analysis developed by Hurley (Note 4) in a study of ethnic diversity and community functioning. Copies of the measure are available upon request from Oscar barbarin, Department of Psychology, University of Michigan, Ann Arbor, Michigan, or from Daniel J. Hurley, Jr., Center for Community Cooperation, 2139 Broad St., Cranston, R.I. 02905. 
Problem-Solving: Style. Responses to the hypothetical problem situations described above were also coded for the individual's level of involvement in the problem-solution. A four-point rating scale was devised which rated involvement of the respondent in solving the problem from passivenonactive to direct-active.

Information Channels. Respondents were asked to identify the channels they used to get information about services and events happening in the community. Types of channels included friends, relatives, newspaper, radio, television, and other. The number of channels utilized by each respondent was scored.

Influence Channels. Respondents were asked to identify the five most influential persons in community in terms of getting things done. Responses were scored in terms of the number of people identified, and the occupations of these individuals (e.g., clergy, government official, etc.).

The questions were administered in a structured interview format that took approximately 30 minutes to complete.

\section{RESULTS}

\section{Interrater Reliability}

Interrater reliability for coding types of community strengths, deficits, and problem-solving styles was determined by calculating the percent of agreement between two of the authors on independent ratings of a random sample of questionnaires. The reliabilities were as follows: $86.96 \%$ for type of community strength, i.e., people, service, physical; $83.05 \%$ for type of community deficit, i.e., people, service, physical; $73.33 \%$ for type of resource relied upon in problem-solving solutions, i.e., personal, informal, formal, or combinations thereof; and $\mathbf{7 1 . 6 \%}$ for problem-solving style, i.e., inactive, indirect-passive, indirect-active, direct-active. Chi-square analyses were then performed to examine differences along these dimensions as a function of racial composition of the community and role.

\section{Intercorrelations Among Survey Items}

Examination of Table I suggests that the survey items intercorrelate in some predictable and understandable patterns. Rating of community satisfaction correlated significantly with the number of perceived community strengths $(r=.42)$ and the rating of probable community support $(r=.36)$. 
Problem Solving, Resource Utilization, and Community Involvement

239

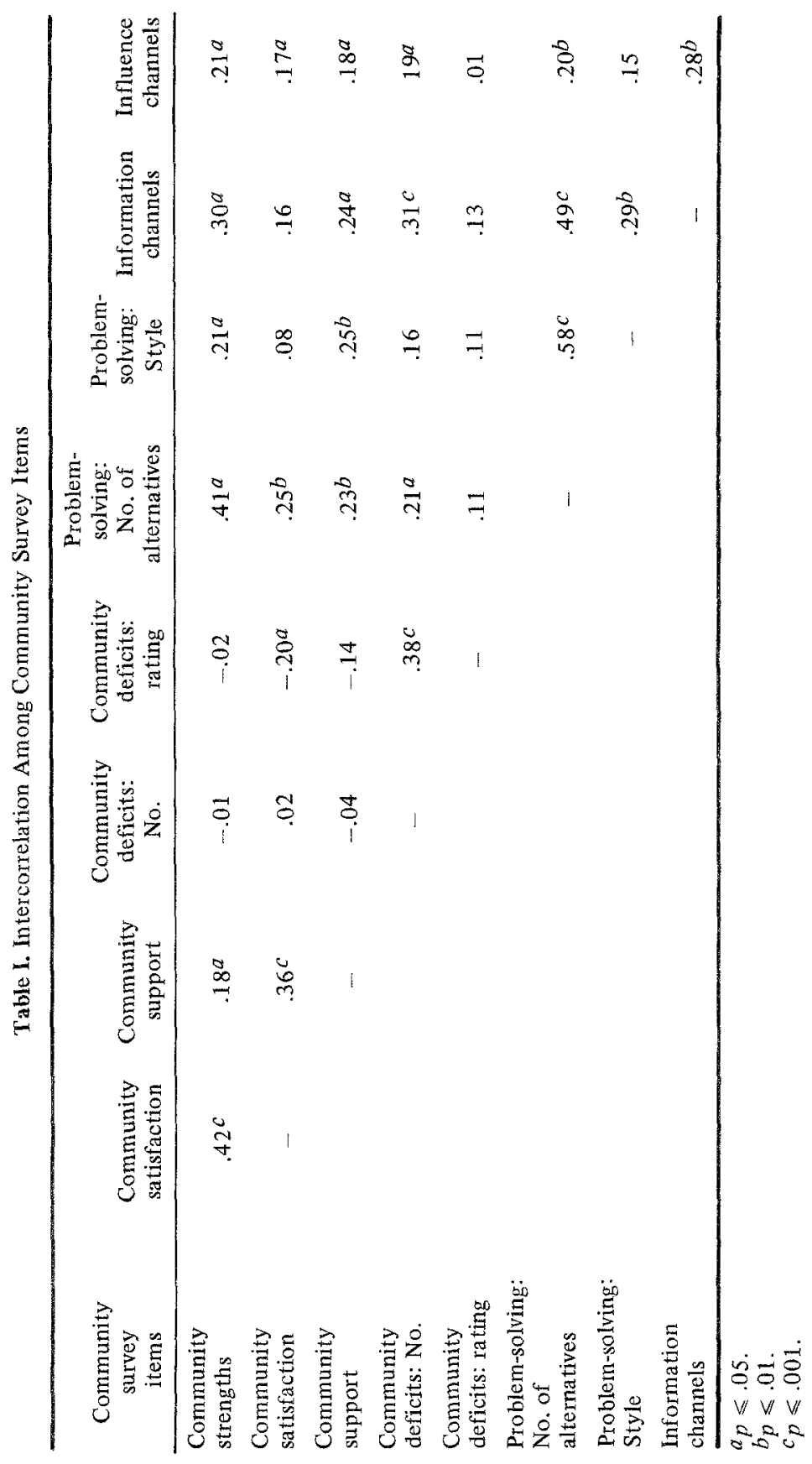


Similarly, the number of perceived community deficits correlated significantly with the rating of severity of community deficits $(r=.38)$. In terms of variables related to competent functioning within the community, the ability to generate a number of alternative problem-solving solutions was directly related to problem-solving style (i.e., level of involvement in problem situations) $(r=.58)$, and one's access to information $(r=.49)$ and influence channels $(r=.20)$.

\section{Multivariate Analysis}

Multivariate analysis of variance (MANOVA) was performed for two factors (i.e., race and role) with two and three groups, respectively (black and white; service provider, active citizen, and inactive citizen), and nine dependent variables (i.e., number of community strengths, degree of community satisfaction and support, number and style of problem-solving alternatives, and number of information and influence channels). The Wilkes' lambda criterion for significance was used. The MANOVA results showed a significant difference for the main effects of racial composition, $F$ $(9,84)=4.99, p \leq 0.01$, and role, $F(18,168)=4.125, p \leq 0.01$, as well as for the interaction effect, $F(18,168)=1.676, p \leq .05$. The means and standard deviations of the groups by race and role are presented in Table II.

Racial Composition of Community. In addition to the overall $F$, several of the univariate $F$ 's were significant at the .01 level, i.e., number of community deficits, rating of community deficits, number of problem-solving alternatives. Respondents in the black community named a significantly greater number of community deficits than did members of the white community, and rated community problems as more severe. Subsequent analysis of the types of deficits cited, though, revealed that members of the black community named a significantly greater number of deficits related to the absence of services than did members of the white community $(62 \%$ vs. $43 \%) \chi^{2}(2)=5.74, p \leq .01$. No significant univariate $F$ values were obtained for degree of satisfaction with life in the community or for perceived likelihood of support from neighbors. Inspection of the standardized discriminant function coefficients suggested that differences in satisfaction and support contributed less to the significant multivariate $F$ than did differences in assessment of deficits.

The communities also differed with regard to problem-solving and utilization of resource networks. Members of the white community cited more alternative solutions to hypothetical problem situations. Analysis of the types of resources utilized showed that members of the white community had a greater reliance on formal services (e.g., mental health personnel, Department of Social Services) than did members of the black community, who showed a significantly greater use of personal and informal resources, i.e., family, friends, civic associations, $\chi^{2}(7)=22.73, p$ 
Table II. Means and Standard Deviations of Dependent Variables by Racial Composition of Community and Members' Role

\begin{tabular}{|c|c|c|c|c|c|c|}
\hline \multirow[b]{2}{*}{ Variable } & & \multicolumn{2}{|c|}{ Race of community } & \multicolumn{3}{|c|}{ Role involvement } \\
\hline & & $\begin{array}{l}\text { White } \\
(N=54)\end{array}$ & $\begin{array}{c}\text { Black } \\
(N=44)\end{array}$ & $\begin{array}{l}\text { Service } \\
\text { provider } \\
(N=24)\end{array}$ & $\begin{array}{c}\text { Active } \\
\text { citizen } \\
(N=32)\end{array}$ & $\begin{array}{c}\text { Inactive } \\
\text { citizen } \\
(N=42)\end{array}$ \\
\hline $\begin{array}{l}\text { Community } \\
\text { strengths }\end{array}$ & $\begin{array}{l}\bar{X} \\
S D\end{array}$ & $\begin{array}{r}1.63 \\
.99\end{array}$ & $\begin{array}{r}1.29 \\
.90\end{array}$ & $\begin{array}{l}1.92 \\
1.02\end{array}$ & $\begin{array}{r}1.66 \\
.87\end{array}$ & $\begin{array}{l}1.09^{c} \\
.88\end{array}$ \\
\hline $\begin{array}{l}\text { Community } \\
\text { satisfaction }\end{array}$ & $\begin{array}{l}\bar{X} \\
S D\end{array}$ & $\begin{array}{l}5.56 \\
1.51\end{array}$ & $\begin{array}{l}5.39 \\
1.83\end{array}$ & $\begin{array}{r}6.04 \\
.99\end{array}$ & $\begin{array}{l}5.62 \\
1.29\end{array}$ & $\begin{array}{l}5.05^{a} \\
2.07\end{array}$ \\
\hline $\begin{array}{l}\text { Community } \\
\text { support }\end{array}$ & $\begin{array}{l}\bar{X} \\
S D\end{array}$ & $\begin{array}{l}5.74 \\
1.58\end{array}$ & $\begin{array}{l}5.50 \\
2.04\end{array}$ & $\begin{array}{l}5.50 \\
1.47\end{array}$ & $\begin{array}{l}6.03 \\
1.09\end{array}$ & $\begin{array}{l}5.40 \\
2.31\end{array}$ \\
\hline $\begin{array}{l}\text { Community } \\
\text { deficits: No. }\end{array}$ & $\begin{array}{l}\bar{X} \\
S D\end{array}$ & $\begin{array}{l}2.11 \\
1.13\end{array}$ & $\begin{array}{l}2.73 \mathrm{C} \\
.79\end{array}$ & $\begin{array}{r}2.83 \\
.76\end{array}$ & $\begin{array}{r}2.69 \\
.64\end{array}$ & $\begin{array}{l}1.91^{c} \\
1.18\end{array}$ \\
\hline $\begin{array}{l}\text { Community } \\
\text { deficits: rating }\end{array}$ & $\begin{array}{l}\bar{X} \\
S D\end{array}$ & $\begin{array}{l}3.61 \\
1.15\end{array}$ & $\begin{array}{l}4.48^{\circ} \\
1.22\end{array}$ & $\begin{array}{r}4.42 \\
.95\end{array}$ & $\begin{array}{l}4.20 \\
1.49\end{array}$ & $\begin{array}{l}3.60^{b} \\
1.11\end{array}$ \\
\hline $\begin{array}{l}\text { Problem-solving: } \\
\text { No. of } \\
\text { alternatives }\end{array}$ & $S D$ & 1.47 & $1.23 b$ & 1.53 & 1.64 & $1.06^{c}$ \\
\hline $\begin{array}{l}\text { Problem-solving } \\
\text { style }\end{array}$ & $\begin{array}{l}\bar{X} \\
S D\end{array}$ & $\begin{array}{r}3.05 \\
.68\end{array}$ & $\begin{array}{r}3.04 \\
.70\end{array}$ & $\begin{array}{r}3.19 \\
.59\end{array}$ & $\begin{array}{r}3.33 \\
.48\end{array}$ & $\begin{array}{l}2.74 c \\
.74\end{array}$ \\
\hline $\begin{array}{l}\text { Information } \\
\text { channels }\end{array}$ & $\begin{array}{l}\bar{X} \\
S D\end{array}$ & $\begin{array}{l}2.19 \\
1.72\end{array}$ & $\begin{array}{l}2.66 \\
1.80\end{array}$ & $\begin{array}{l}3.17 \\
2.37\end{array}$ & $\begin{array}{l}2.75 \\
1.52\end{array}$ & $\begin{array}{l}1.69^{c} \\
1.22\end{array}$ \\
\hline $\begin{array}{l}\text { Influence } \\
\text { channels }\end{array}$ & $\begin{array}{l}\bar{X} \\
S D\end{array}$ & $\begin{array}{l}2.44 \\
1.81\end{array}$ & $\begin{array}{l}2.25 \\
1.87\end{array}$ & $\begin{array}{l}3.21 \\
1.74\end{array}$ & $\begin{array}{l}2.75 \\
1.78\end{array}$ & $\begin{array}{l}1.57^{c} \\
1.64\end{array}$ \\
\hline
\end{tabular}

$a_{p} \leqslant .05$, univariate $F$ test.

$b_{p} \leqslant .01$, univariate $F$ test.

$c_{p} \leqslant .001$, univariate $F$ test.

$\leq .01$. Similar differences emerged when respondents were asked to name persons who were influential in the community in terms of getting tasks accomplished, $\chi^{2}(12)=62.79, p<.01$. For members of the white community, town officials, county officials, and local business persons were the three most frequently cited responses. Members of the black community perceived town officials, civic association members, and clergy as the most influential individuals. In addition, members of the black community more frequently responded "no one" to this question than did members of the white community ( $16 \%$ vs. $2 \%$ ).

Role of Community Member. Extensive differences emerged in the way people related to their communities as a function of their role as either service providers, active citizens, or inactive citizens. Univariate analyses yielded significant $F$ values for all variables except rating of community support, and most of these were significant at the 0.001 level.

Service providers were able to name more community strengths than active or inactive citizens, and reported a high degree of satisfaction working within these communities. Service providers, nonetheless, cited a greater number of community deficits than residents themselves, and rated com- 
munity problems as more severe. Subsequent $\chi^{2}$ analyses revealed no significant differences in the types of community strengths and deficits named. Service providers displayed an involved problem-solving style, but tended to rely upon formal resources to a greater degree than active or inactive citizens, $\chi^{2}(14)=79.54, p \leq .001$.

Like the service providers, active citizens were able to name more community strengths and deficits than inactive citizens, and experienced a considerably greater degree of satisfaction with their community than did inactive citizens. What characterized this group most strikingly was their use of community resources. Active citizens were able to cite the greatest numbers of alternatives in response to problem situations and showed a highly involved problem-solving style. Active citizens showed the greatest flexibility in resource utilization, as evidenced by their greater ability to draw upon combinations of formal, informal, and personal resources, $\chi^{2}(4)=58.75, p \leq .001$.

Inactive citizens presented the most contrasting pattern. These citizens cited the fewest community strengths and deficits, and experienced the greatest dissatisfaction with their community. They cited the fewest alternatives to a variety of problem situations and employed a much more passive problem-solving style. The problem solutions that inactive citizens did cite were significantly less varied than those of active citizens and service providers, who were often able to use some combination of formal, informal, and personal resources. Similarly, inactive citizens used fewer information sources to learn about resources. When asked to name important influence channels (i.e., powerful persons) in their community, over onethird of the ianctive citizens replied "none," or "don't know."

Interaction Effects. Although the multivariate $F$ ratio for the interaction of race and role was significant $(p \leq .048)$, none of the univariate $F$ s were significant. Examination of the standardized discriminant function coefficients and subgroup means suggest that some of the variance is attributable to differences in the way that inactive citizens in the black and white towns experience their communities. Inactive citizens in the black community had access to fewer influence channels, generated a lesser number of alternative solutions, and had a more passive problem-solving style than inactive citizens in the white community. Inactive citizens in the black community also cited a greater number of community deficits and a lesser number of community strengths.

\section{DISCUSSION}

The most striking differences between members of the black and white communities were not in perceived sense of satisfaction with, and support 
from, their communities, but in black community members' acknowledgment of service-related community deficits, and in their greater utilization of informal community processes. Thus, at least in this instance, a vocal dissatisfaction with the lack of formal services does not necessarily signal a more pervasive dissatisfaction with life in one's community. One might speculate that in response to a perceived (and perhaps actual) absence of formal services, members of the black community developed a greater reliance on informal community resource networks.

One pattern that emerges is the apparent relationship between an effective problem-solving style, perceived access to some community resource network, and an experience of probable support from community members. For inactive citizens, one might speculate that a passive and noninvolved problem-solving style could result in estrangement from informal community networks. This suggests that one important area of study is how individuals come to involve themselves and maintain involvement with informal networks.

Such patterns may also be moderated by the particular community. Inactive citizens in the black community, for example, displayed less satisfaction than inactive citizens in the white community. A tentative interpretation is that the passive and uninvolved style of inactive citizens may have been particularly ill-suited to the black community, where membership in informal resource networks seemed more crucial for satisfying needs. Similarly, Holohan et al. (Note 2), in a study of social support, race, and mental health, found that blacks low on neighborhood integration reported a markedly higher number of psychiatric symptoms than whites who were similarly low on neighborhood integration. Their conclusion is similar to that of Bowser (1981), who states: "those blacks who have a higher predisposition to mental illness are those who experience racist behavior but receive no countering social support from their community's social life." Analysis of resource network patterns may provide strategies for intervention, as well as identifying at risk groups. Knowing that a particular group of people rely on particular networks (i.g., inactive citizens tended to cite clergy as influential persons), one could try to target one's intervention efforts through those relevant networks (e.g., Turner, Kimbrough, \& Traynham, 1977).

\section{IMPLICATIONS}

Some limitations of this study should be kept in mind. The study is based on a limited data set of only two communities, and relies solely on self-report data. The smaller size of the black community may be one alternative explanation for its greater reliance on informal networks, and the 
selection of active citizens on a volunteer rather than random basis might have introduced unknown sources of bias. Although socioeconomic differences between groups were not apparent to interviewers, for example, data on income levels were not available to empirically test this. Nonetheless, the authors feel that the study raises several issues that may prove useful for those involved in community analysis.

First, patterns of strengths and deficits vary among communities, requiring an examination of both evaluative (e.g., satisfaction) and process (e.g., resource utilization) dimensions. Instead of asking whether a community is "competent," one should ask how competent the community is along a variety of dimensions for dealing with particular tasks. The greater reliance on informal networks by black community members may be particularly well suited for some types of problems (e.g., informal day-care arrangements; sheltering a family displaced by a natural disaster), but not for others (e.g., advocating for resources from the county political system).

Second, our findings regarding role differences raise the question of on whose perception of need-providers or potential consumers-should community resources be allocated. Service providers tended to rate community problems as more severe than did residents themselves, especially inactive citizens. This difference may represent a more informed opinion on the part of service providers, or on the other hand, a more self-serving assessment that benefits the survival of the service system. As a solution to this dilemma, Siegel, Attkisson, and Carson (1978) suggest a process of convergent analyses for integrating divergent perspectives of service providers and consumers.

The pattern of resource utilization and problem-solving shown by active citizens may be instructive to mental health professionals in suggesting some of the components of effective "indigenous community problemsolving." Early reports of indigenous community workers tended to emphasize their "savvy" and ability to "bridge the gap" between the agency and the community (Pearl \& Riessman, 1965; Reiff, 1966), but failed to specify what particular skills or attributes contributed to such success. Recent empirical studies of paraprofessional effectiveness have tended to focus on more clinical and interpersonally oriented skills (e.g., D'Augelli \& Levi, 1978; Schag, Loo, \& Levin, 1978). Analysis of the "networking" and "problem-solving" skills of persons who are effective agents in their communities may serve as a reasonable intial step in articulating dimensions that may be important for the effective paraprofessional in the community.

An initial question raised by this study was how system characteristics influence individual experience of community life. What do the results of this study suggest in terms of future research strategies? The authors were struck by the extent to which differences in members' experiences seemed related to differential involvement in various resource networks. Similarly, 
a large body of research has talked about the impact of varying social networks upon individual health and well-being (Hammer, Makiesby-Barrow, \& Gutwirth, 1978; Mitchell \& Trickett, 1980), while at a broader level, Sarason (1976) has talked about viewing communities in terms of interlocking networks. The notion of social network might serve as a useful mediating variable between larger systems characteristics (e.g., population turnover, ethnic diversity, families below poverty level, etc.) and individual experience of community. Such a conceptualization would allow one to examine both the processes by which individuals involve themselves in immediate social network groupings, and the processes by which communities encourage or hinder the maintenance of effective and ineffective social network patterns.

\section{REFERENCE NOTES}

1. Glynn, T. J. Community psychology and psychological sense of community: Measurement and application. Paper presented at the meeting of the American Psychological Association, Toronto, Canada, August 1978.

2. Holohan, C. J., Betak, J. F., Spearly, J. L., \& Chance, B. L. Natural helping systems and mental health in minority communities. Paper presented at the meeting of the American Psychological Association, New York, September 1979.

3. Barbarin, O., \& Hurley, D. Community survey: An assessment of community climate and processes. Unpublished manuscript, 1974.

4. Hurley, D. Relationship between cultural diversity and community effectiveness: $A$ comparative analysis of community systems. Doctoral dissertation, University of Maryland, 1977.

\section{REFERENCES}

Bowser, B. Racism and mental health: An exploration of the racist's illness and the victim's health. In. O. Babarin, P. Good, M. Pharr, \& J. Suskind (Eds.), Institutional racism and community competence. Rockville, Md.: Dept. of Health and Human Services, 1981.

Campbell, A., Converse, P. E., \& Rodgers, W. L. The quality of American life: Perceptions, evaluations, and satisfactions. New York: Russel Sage Foundation, 1976.

Carr, T. H., Dixon, M. C., \& Ogles, R. M. Perceptions of community life which distinguish between participants and nonparticipants in a neighborhood self-help organization. American Journal of Community Psychology, 1976, 4, 357-366.

D'Augelli, A., \& Levi, M. The verbal helping skills of trained and untrained human service paraprofessionals. American Journal of Community Psychology, 1978, 6, 23-32.

Froland, C., Pancoast, D., Chapman, N. \& Kimboko, P. Linking formal and informal support systems. In B. Gottlieb (Ed.), Social networks and social support. Beverly Hills, CA.: Sage, 1981.

Garbarino, J., \& Sherman, D. Identifying high-risk neighborhoods. In J. Garbarino \& H. Stocking (Eds.), Protecting children from abuse and neglect. San Francisco: JosseyBass, 1980.

Gottlieb, B. H. The primary group as supportive mileu: Applications to community psychology. American Journal of Community Psychology, 1979, 7, 469-480. 
Gourash, N. Help-seeking: A review of the literature. American Journal of Community Psychology, 1978, 6, 499-517.

Greenberg, M. A concept of community. Social Work, 1974, January, 64-73.

Hammer, M., Makiesby-Barrow, S., \& Gutwirth, L. Social networks and schizophrenia. Schizophrenia Bulletin, 1978, 4, 522-545.

Hurley, D., Barbarin, O., \& Mitchell, R. An empirical assessment of racism in community functioning. In O. Barbarin, P. Good, M. Pharr, \& J. Suskind (Eds.), Institutional racism and community competence. Rockville, Md.: Department of Health and Human Services, 1981.

Iscoe, I. Community psychology and the competent community. American Psychologist, $1974,29,607-613$.

Lewis, O. The culture of poverty. Scientific American, 1966, 215, 19-25.

Marans, R. W., \& Rodgers, W. Toward an understanding of community satisfaction. In A. H. Hawley \& V. P. Rock (Eds.), Metropolitan America: In contemporary perpective. New York: Wiley, 1975.

Mitchell, R. E., \& Trickett, E. J. Social networks as mediators of social support: An analysis of the effects and determinants of social support. Community Mental Health Journal, $1980,16,27-44$.

Moynihan, D. P. The Negro family: A case for national action. Washington, D.C.: Office of Policy Planning and Research, U.S. Department of Labor, 1965.

Padilla, A. Competent communities: A critical analysis of theories and public policy. In O. Barbarian, P. Good, M. Pharr, \& J. Suskind (Eds.), Institutional racism and community competence. Rockville, Md.: Department of Health and Human Services, 1981.

Pearl, A., \& Reissman, F. New careers for the poor: Nonprofessionals in human service. New York: The Free Press, 1965.

Reiff, R. Mental health manpower and institutional change. American Psychologist, 1966, $21,540-548$.

Richardson, J. D., \& Scutchfield, F. D. Priorities in health care: The consumer's viewpoint in an Appalachian community. American Journal of Public Health, 1973, 63, 79-82.

Sarason, S. The psychological sense of community: Prospects for a community psychology. San Francisco: Jossey-Bass, 1974.

Sarason, S. Community psychology, networks, and Mr. Everyman. American Psychologist, 1976, 3l, 317-328.

Schag, D., Loo, C., \& Levin, M. The Group Assessment of Interpersonal Traits (GAIT): Differentiation of measures and their relationship to behavioral response modes. American Journal of Community Psychology, 1978, 6, 47-62.

Shaver, K., \& Cole, G. Perceived community problems: The differing views of leaders and residents. JSAS Catalog of Selected Documents in Psychology, 1973, 3, 1-25.

Siegel, L. M., Attkisson, C. C., \& Carson, L. G. Need identification and program planning in the community context. In C. C. Attkisson, W. A. Hargreaves, M. J. Horowitz, \& J. E. Sorenson (Eds.), Evaluation of human service programs. New York: Academic Press, 1978.

Turner, J. T., Kimbrough, W. W., \& Traynham, R. N. A survey of community perceptions of critical life situations and community helping sources as a tool for mental health program development. Journal of Community Psychology, 1977, 5, 225-230.

Warren, D. Explorations in neighborhood differentiation. Sociological Quarterly, 1978, 19, 310-313.

Warren, D. I. Assessing community support systems in different types of neighborhoods. In J. Garbarino \& H. Stocking (Eds.), Protecting children from abuse and neglect. San Francisco: Jossey-Bass, 1980.

Zautra, A., Beier, E., \& Cappel, L. The dimensions of life quality in a community. American Joumal of Community Psychology, 1977, 5, 85-97. 